\title{
Citizen Diversity in eGovernment Research: Moving the Field Forward
}

\author{
Annika Andersson \\ Örebro University, \\ Sweden \\ annika.andersson@oru.se
}

\author{
Mathias Hatakka \\ Örebro University, \\ Sweden \\ mathias.hatakka@oru.se
}

\author{
Hannu Larsson \\ Örebro University, \\ Sweden \\ hannu.larsson@oru.se
}

\author{
Karin Hedström \\ Örebro University, \\ Sweden \\ karin.hedstrom@oru.se
}

\begin{abstract}
Whereas broad launch of public e-services ensures equal and homogenous treatment of citizens, citizen diversity is often set aside. By means of a literature study we describe how research has addressed diversity in the field of e Government. we analyzed the papers according to the following codes: group; application domain; unit of analysis; and technology in use or design. Results showed that the most common application domain was e-services with access and use as the most common units of analysis. The most frequently researched groups are based on classical socio-demographic variables such as economy, education and age. Also, the majority of papers discussed services in use. We conclude by suggesting that future research focuses underrepresented user groups; adds further granularity to the classical sociodemographic variables; identifies groups within groups; targets policies and policy implementation; and changes focus from use to development. We also call for conceptual clarity of the concept 'diversity'.
\end{abstract}

\section{Introduction}

In the name of digitalization, our society is seeing a rapid and broad launch of public e-services to citizens. This includes not only digitalization of processes or the use of computers as a support for decisions, but also an increasing use of computers as actual decision-makers. Today, almost on a daily basis, one can read about public authorities implementing Artificial Intelligence (AI) in their daily routines. According to one newspaper article, the Swedish Social Insurance Agency implements AI in order to make the processing of cases more democratic: "Artificial intelligence will guide case workers to the right decision. In order to be legally consistent all over the country we will need more assistance from computers. AI will help with the ground-work so that it will be as equal as possible" [1]. The use of information systems in public sector is today positioned on the border between computer-based case handling, rule-based autonomous expert systems to fully-fledged self-learning AI- systems. In the near future AI capabilities are expected to reinforce human capability and evolve from toady's rule-based systems to supervised machine learning and in the end to unsupervised and self-aware learning systems [2]. In a public sector increasingly using automated decisionmaking and AI-solutions for its interactions with citizens it is important to consider citizen diversity in the design of these systems. Whereas new technological advances can support equal and homogenous treatment of citizens different needs, based on the diversity of citizens, are still often set aside or ignored.

In a society where alternatives to digital services are rapidly decreasing, we need to ensure that not only the majority of 'normal' users can access and use these services, but that all citizens of our society can do so. We need to make sure that research in eGovernment supports practice by addressing these issues in a clear and innovative manner.

In acknowledging the importance of diversity in the development of public e-services, this study aims to describe the focus of eGovernment research when diversity among citizens is addressed. We are looking at a broad range of diversity issues so as to enhance our understanding of how diversity is being addressed, or not, in eGovernment research. More specifically, we are interested in investigating which user groups are discussed in research in relation to diversity, which type of services, or applications, that are focused, which factors (e.g., political deliberation or use of e-services) that are targeted and when, in the systems development lifecycle, the study is conducted, i.e., in the design of the services/applications or when they are being used by citizens.

Based on this description we intend to propose needs for future research in order to move the field forward and contribute to a true 'design-for-all'-policy in public sector e-service delivery.

The paper is organized as follows. The next section elaborates on the notion of diversity. Thereafter the method for the literature study is described. The results of the literature study are then presented, followed by a 
discussion of the findings. The paper then concludes with a suggested agenda for future research.

\section{Citizen diversity}

There is not a unified definition of citizen diversity in the field of eGovernment, but some examples of how it has been used will be presented below. Citizen diversity has been often been defined in broad terms such as different perspectives that result in cultural groups having behavioral differences as well as identity differences in relation to other groups [3] or it is defined by e.g., ethnicity, gender and age "which are legally protected from discrimination" [4: p.214]. Whereas the Robinson's [4] delimitation to groups that are legally protected from discrimination is appealing by its straightforwardness, it excludes groups that are not yet defined by law and the definition will also vary depending on which country citizen diversity is being discussed. Larkey's [3] more open definition leaves too much room for interpretation of what a 'cultural group' is (or - what is culture?). In eGovernment research, the concept is applied in many different ways with varying degrees of problematization of its meaning and its implication for practice.

Research on diversity in public sector often concerns how managers can work with different diversity policies [5]. Research and practice concerning the management of equal opportunities in public sector refer to this work as "managing diversity" [6]. When diversity is discussed in relation to citizens' Internet use and access the most common concepts used are 'digital divide', 'digital inclusion' or 'digital exclusion'. These digital divides are often described in relation to other social inequalities [7] focusing gender, age, education [8] or country diversity [9]. The challenging situation for people with disabilities is often discussed [10] and societal aging is also a re-occurring theme [11]. Another theme is the role of public libraries have for providing essential services 'for all' [12]. In this field of research we also find many calls for public policies [13] and warnings not to parallel inclusion with adaptation [14]. Finally, there are a few calls for more norm-critical perspectives in research in public sector [e.g., 15].

\section{Method}

The purpose of this literature review is to explore and map relevant research concerning citizen diversity in eGovernment research. We do so by following Webster and Watson's [16] strategy for how to conduct literature reviews in Information Systems (IS) research.
Literature reviews are critical to strengthening the IS field and are useful as a ground for theory development, uncovering areas where more research is needed, and synthesize areas where a plethora of research already exists [16].

\subsection{Selection of paper}

In the study, papers were searched for in the Digital Government Reference Library (DGRL) version 15.5 ${ }^{1}$. The reference library contains references to 12,546 peer-reviewed academic papers in the areas of digital government, digital governance, and digital democracy. The library covers the period from 1981 and consists of entries from core eGovernment journals and conferences, as well as relevant publications from other journals, many of which are in the IS field. The library thus covers the vast majority of research relevant to the eGovernment field.

To search the reference library, we used the reference management software EndNote. In order to cover as many relevant papers as possible we first did a thorough search in order to find the right key words (i.e., how do people label their research on diversity in eGovernment?). For this we selected a few top journals dedicated to eGovernment (e.g., GIQ, EJEG, IJEGR) and selected ten papers relevant to our topic from each journal and wrote down all keywords used in these papers. We stopped our search for keywords when the same keywords kept re-appearing in the papers. Keywords used were diversity, inclusion, exclusion, digital divide, equality, inequality and discrimination. We set the timeframe for investigation from 2004 to the end of 2019, thus capturing the past 16 years of research in the field.

The initial search resulted in 658 papers. All 658 papers were investigated further to see if they were relevant for the study. This was done by dividing the papers between the authors and where each author independently looked at the title of the paper and read the abstract. This resulted in 74 papers that were found relevant. The 74 papers were chosen by including only papers that were related to our aim by focusing on diversity of citizens in relation to eGovernment. Thus, papers that did not deal with diversity and citizens, or only mentioned one or more of the keywords in passing were excluded. The large group of discarded papers dealt with issues such as diversity in internal workgroups, biodiversity, inter-governmental cooperation, diversity in theories on eGovernment and varieties in technologies used for e-services. The 74 papers were then further scrutinized by all authors who

\footnotetext{
${ }^{1}$ http://faculty.washington.edu/jscholl/dgrl/
} 
this time also read the findings and discussion/conclusion in the papers. We were not able to find the full-text versions of 4 papers and some additional papers were excluded since they did not deal with diversity in the way we have defined it. The authors were in agreement on the selection of the papers and after the final scrutiny we ended up with 55 papers for the analysis.

\subsection{Analysis of the papers}

During the analysis we coded the papers based on four variables. The selection of categories for reviewing the papers was based on Grönlund and Andersson's [17] method for assessing the nature of eGovernment research. Whereas this method consists of a vast number of categories to investigate, we chose those who were closest to our aim - e.g., "target group" was seen as relevant given our aim to capture citizen-groups whereas a category concerning "rigor" in method could be discarded since our aim was not assess the quality of these papers but rather the focus of them. The variables were:

- Diversity groups - i.e., which citizen groups are focused in the papers, e.g., people with disabilities, gender, or elderly citizens.

- Application domain - i.e., type of eGovernment services/applications that are focused, e.g., use of e-services or participation in political deliberations.

- Unit of analysis - i.e., factors that are being analyzed in relation to diversity, e.g., access to information, access to services or software design aspects.

- Diversity in use or design - i.e., when in the software lifecycle, are the diversity aspects focused,e.g., when the citizens use the services or when the software/services are designed and developed.

We started the coding by randomly selecting five papers for emergent coding [18] where two of the authors independently coded the same papers. After this the result of the coding was compared for consistency in the coding. For two of the variables we found discrepancies between the coding. Those variables were discussed until a consensus was made on how to code them. The rest of the papers were divided between two of the authors and coded independently.

For the analysis of the papers we used conventional content analysis [19] where the new categories for our selected variables were derived from the text in the papers. The categories were, hence, based on the content being analyzed rather than based on any predefined variables. Several of the papers were, however, coded as belonging to two or more categories. Hence, the total numbers in the results sometimes are greater than the total number of papers being analyzed (55). For example, several papers focused on two or more user groups - e.g., people with disabilities and digitally excluded citizens -and those papers were categorized as both. After the initial coding, we revisited the codes again to see if some codes needed to be merged or split. For example, for the variable unit of analysis we had the codes "design experiences" and "design challenges" and these were later merged into "design for diversity".

\section{Result}

In the results we present the findings based on the four variables: application domain; unit of analysis; diversity groups; and in use or design. For each of the categories we exemplify the findings with papers included in the literature review.

\subsection{Application domain}

The most common application domain is to study diversity aspects in relation to use and design of public e-services (23 papers). The second most common domain is general use of IS, e.g., 'surfing/browsing', accessing private websites, use of word formatting software, use of e-mail (16 papers) followed by political participation (12 papers). Table 1 summarizes the applications domains found in the review.

Table 1. Summary of application domain

\begin{tabular}{|l|l|}
\hline E-services & 23 \\
\hline General use of IS & 16 \\
\hline Political participation & 12 \\
\hline Policy discussions & 7 \\
\hline Use in research & 1 \\
\hline Design of IS & 1 \\
\hline
\end{tabular}

Studies that focus on e-services do so from a variety of perspectives, e.g., gender inequality in use of government websites [20], hearing-impaired ability to access emergency services [21] or access to e-services via library services [22]. What is common (with some exceptions) for studies on e-services is that they look at a wide variety of factors, such as age, gender, educational background etc., affecting the use of the services, and they often do so by a statistical analysis of the factors. Studies on diversity and e-services usually present two types of results: 1) a model or framework to 
explain the use of the services for different user groups, e.g., a performance assessment model [23] or an extended TAM model [24], or 2) conclusions about different socio-demographic/economic variables' effect on the use [e.g., 20, 25].

The second most common application domain is papers that do not look at any specific service or platform. The studies rather look at the use of IS in general. Such studies include reviews of inclusion/exclusion [14, 26], IT skills and digital divide, or more general use of Internet such as accessing banking sites or shopping and browsing for information $[10,13]$.

Eleven papers focused different aspects of online political participation and deliberation. These papers fall into the e-democracy domain which can be defined as "[...] the use of information and communication technologies to engage citizens, support the democratic decision-making processes and strengthen representative democracy. [...]" [27: p.2]. Different aspects of political participation are targeted in the papers, for example, citizens inclusion in political decisions (smart cities) [28] or how to facilitate the inclusion of youths in public debates [29]. Commonly, the papers stress the importance of designing services and platforms for all citizens, or that there is a risk that citizens will be excluded from political processes and have their human rights violated [30].

Policy discussions and implications were a focus in seven papers. In these papers, policies were often discussed in combination with another application domain such as use of e-services [22] or discrimination of people with disabilities in on-line political participation [31]. However, two papers argue for the importance of citizen engagement and participatory methods in policy making when designing e-services $[32,33]$.

Finally, one paper was categorized as use in research since it focuses on methods for conducting eGovernment research related to social ageing [11].

\subsection{Unit of analysis}

The most common unit of analysis in the reviewed papers is access and use of public e-services (23 papers). The second most common unit of analysis is papers that focus on how to design services, or platforms, for diverse user groups (11 papers). In addition, we found 5 other categories ranging from access to technology to papers that focus the quality of arguments in the public sphere. Three papers were difficult to categorize since focus was not spelled out, but we labelled them as 'Government interference and control', eGovernment digital divide and research models. Table 2 summarizes the findings.
Table 2. Summary of unit of analysis.

\begin{tabular}{|l|l|}
\hline Access and use of services & 23 \\
\hline Design for diversity & 11 \\
\hline Participation and deliberation & 6 \\
\hline Digital literacy & 4 \\
\hline Access and use of Internet & 3 \\
\hline Argumentation & 2 \\
\hline Social interaction & 1 \\
\hline Government interference and control & 1 \\
\hline eGovernment digital divide & 1 \\
\hline Research models & 1 \\
\hline
\end{tabular}

Papers that focus access and use of e-services usually look at how digitally excluded groups can access and use e-services. The reasons for the digital exclusion can range from user groups with low digital literacy, to individuals with disabilities (e.g., the hearing-impaired) that make it difficult for them to use the services. For example, in a study by Ferri and Favalli [10] EU policies and rules were examined related to digital literacy and the authors argued that the Internet "has the potential to foster social inclusion of people with disabilities" (p.1), but that "the situation for people with disabilities remains challenging in terms of access to new technologies, and in particular websites and other online services" (p.14). Other studies come to similar results [e.g., 34, 35]. Another common type of study is to look at different socio-demographic/economic factors and how they relate to use of e-services. For example, [20] looks at the demand and use of Korean government websites and concludes that there is no persistent gender divide, but family characteristics is a determinant for demand and that there is a divide in access and use of eGovernment services based on the users' education and occupation.

Eleven papers analyze different design and develop issues related to services and platforms for diverse user groups. Often, the end-users are not involved in the design of public services and the users' needs are therefore sometimes guessed rather than analyzed [36]. This may of course cause problems since public services need to be inclusive and the end-users can be diverse with different abilities and preconditions. As a way to "fix" the gap between developers and end-users, researchers call for participatory approaches in the design and development of these services [e.g., 37, 38, 39]. For example, responding to the need to include endusers in the design process, [37] develops a "G2C eService Co-design Framework" where the 
"operationalized design process provides an actionable approach that can be used to design digital services in a governmental context" (p. 2546) including citizens as a stakeholder.

Papers focusing on participation and deliberation either look at how citizens of diverse user groups can be involved in public, or political, participation and deliberations [e.g., 29], or they look at sociodemographic factors and how they affect users' participation [e.g., 8]. In addition to the above mentioned categories of unit of analyses we also found papers where the unit of analysis was on argumentation in public debates [e.g., 9], papers focusing digital literacy [e.g., 26], social interaction [e.g., 40] and access and use of Internet [e.g., 41].

\subsection{Diversity groups}

The most common groups to study are based on socio-demographic variables such as gender, age, income, education level, ethnicity (23 papers). 16 papers discuss diversity but do not specify any particular group of people. The single group most commonly mentioned is people with disabilities ( 8 papers) followed by the elderly ( 3 papers). 8 papers talk about the 'digitally excluded', 2 papers specifically discuss gender, 1 paper addresses migrants, another one addresses cultural factors and a final paper specifically targets the youth. Table 3 summarizes the applications domains found in the review.

Table 3. Summary of the groups focused on in the papers.

\begin{tabular}{|l|l|}
\hline Various socio-economic variables & 23 \\
\hline Non-specific & 16 \\
\hline People with disabilities & 8 \\
\hline The digitally excluded & 8 \\
\hline The elderly & 3 \\
\hline Gender diversity & 3 \\
\hline Migrants and immigrants & 1 \\
\hline Cultural factors & 1 \\
\hline The youth & 1 \\
\hline
\end{tabular}

The studies that use classical socio-demographic variables such as gender, age, income, education level and ethnicity are the most frequent and some of these studies are published every year during our time of investigation (from 2004 to 2019). These studies investigate e.g., how gender, age, education and ethnicity affect participation in public discussion [8] or how those who have a lower socioeconomic status use governmental services to a lesser degree [42]. The many papers that do not specify any particular citizen group typically discuss how to design life-events for 'everybody' [43] and the papers referring to the digitally excluded can discuss how public libraries make access to e-services possible for 'the excluded' [12]. The disabled are usually researched based on accessibility factors such as whether websites and other online services are accessible and whether new legislation is needed [10]. The elderly are often discussed in relation to them having disabilities or them belonging to an economically disadvantaged group [44]. One study pointed out that there is a lack of eGovernment research on societal aging [11]. The two papers that specifically discussed gender found that gender, as in being a man or a woman, did not affect access to and use of eGovernment services [e.g., 20]. The one paper that addressed migrants found that Chinese migrant worker lacked motivation, intellectual capacity, and social support to access e-services [45]. The paper that addressed cultural factors showed that cultural attitudes, i.e. moral beliefs regarding social interaction, explained the use of social Internet use [40] and the paper addressing young people showed that youth affected engagement in e-participation positively [29].

\subsection{Diversity in technology use or design}

Table 4 below summarizes where in the IS lifecycle diversity is studied in the papers. As seen in the figure, the majority of the papers (40) looks at diversity aspects when different government services, platforms etc., are being used. 16 papers focus on diversity aspects when services are being designed and developed. One paper looks at diversity when conducting eGovernment research.

Table 4. Summary of when diversity is being studied in the paper.

\begin{tabular}{|l|l|}
\hline In use & 43 \\
\hline In design & 16 \\
\hline In research & 1 \\
\hline
\end{tabular}

The papers that focus on diversity aspects in the use of IS, analyze diversity in a variety of different areas. For example, [22] and [12] study the role of public libraries in providing access- and assistance to digital services for the digitally excluded. Both studies come to similar conclusions regarding the libraries' ability to provide "broadband, digital literacy skills, and facilitate access to economic, learning, health, and civic engagement opportunities" [12: p.95] to user groups that are digitally excluded. 
Another, more common, type of study on the use of IS in public sector is to focus different sociodemographic or socio-economic factors and how they affect citizens' use of services. For example, [14] study different socio-economic factors' influence on use of services and conclude that "technology should adapt to different user profiles and not the other way around" [14: p.167].

While the results of the studies can vary depending on application area, and type of user group included in the study, most studies come to similar conclusions that different personal characteristics (such as age, disabilities or education level) can impact the citizens' ability to access and use essential public services.

Studies on diversity aspects in the design and development of public services have many different themes. For example, [46] focuses the design of services for major tourist events, and [28] study citizens' participation in the development of smart cities. A common theme in the papers that focus on design is that many of them advocate participatory approaches where the users are included in the design- and development process. To exemplify, [39] argues that engagement of citizens in design of services has several benefits. The potential benefits include more personalized services, a wider choice of innovative ideas, better quality of life by tackling the most important issues and lowering the costs by focusing on issues that users see value in.

Finally, one paper was categorized as focusing on diversity aspects in research. The paper [11] focuses on potential theories, models and concepts in eGovernment research related to societal aging.

\section{Discussion}

The results of our literature review revealed that research on diversity, and which groups that are at risk of having a disadvantage, is based on classical sociodemographic variables such as economy, level of education, age and gender. Within these groups no further distinction is made apart from notable exceptions from Macdonald and Clayton [35] and Silva, Matos and Martinez-Pecino [13], who added further granularity to the analysis by investigating sociodemographic variables such as gender and income for the two groups elderly and disabled. This means that important aspects of intersectionality are to a big part ignored [47]. The second most common category here was the nonspecified group (16 papers) or the somewhat vague group referred to as the 'digitally excluded' (8 papers). The most common application domain was, not surprisingly, the general 'e-services' (23 papers), followed by a category of paper discussing general use of IS (16 papers) and political participation (12 papers). What is measured in the papers (unit of analysis) is access and use (23 papers) and design for diversity (11 papers). The vast majority of the papers (40 papers) discussed services in use whereas only 16 papers were forward-looking by (also) discussing future developments of services.

\subsection{An agenda for future research}

This study set out to describe how diversity among citizens is addressed in eGovernment research. Our results showed that the most common application domain was e-services with access and use as the most common unit of analysis. The most frequently researched groups are based on classical sociodemographic variables such as economy, level of education, age and gender and that this categorization was rarely broken down for further analysis such as groups within groups nor were any new groups, such as migrants, included. We also found that the vast majority of the papers discussed services in use, not forwardlooking towards what could, or should, be the case. We conclude this paper by suggesting the following future directions for research on diversity: define citizen diversity; focus underrepresented user groups; further the granularity in classical sociodemographic variables; identify groups within groups; target policies and policy implementation; and change focus from use to development.

As the main contribution of this study, we suggest the following agenda for future research:

1. Define diversity in the eGovernment field. As discussed in the Introduction there is no clear and agreed upon definition of what citizen diversity in eGovernment is. In the method section we also discussed how using 'diversity' as a keyword generated a large amount of papers that dealt with many aspects that were no way near our intentions in with this paper. As our first suggestion for future research we therefore call attention to the necessity for researchers to generate a shared understanding of how citizen diversity should be defined in the field of eGovernment. We suggest that this could be done by dedicating a conference-track or special issue in a journal for this purpose.

2. More focus on underrepresented user groups. Our results showed that several groups of people are underrepresented in eGovernment research on diversity. One apparent excluded group in the literature is migrants who was only focused in one of the papers [45]. Considering the increased flow of migrants, as well as the vulnerability of this 
group, more research is needed on how eGovernment services, can, and should, be designed in order to involve and benefit these diverse needs. Thus, researchers, in their surveys and other data collection methods, need to also include citizens that do not officially reside in the country under investigation. Other groups that we would also like to see included in future data collections are e.g., indigenous minorities, the LGBTQ community, religious and political minorities.

3. Further the granularity of the classical socio-demographic variables. Our results showed that the vast amount of research on citizen diversity related to classical sociodemographic groups such as economy or age (see Table 3). Whereas these categorizations have proven to be important predictors of use, we believe that much knowledge about citizen diversity can be gained by adding a further level of analysis within each group by combining categories or by adding further subcategories to each category. E.g., following the example of [35] who investigated access and use of the disabled, they then added a further dimension to the analysis by investigating the sociodemographic variables gender (also with recognition of alternative gender identities), level of education and income within this group. Researchers also need to embody the idea of intersectionality and how different forms of discrimination and exclusion is related to each other [47]. This is vital in order to avoid reductionist studies relying on the assumption of variables as being separate.

4. Identifying citizen groups within groups. On a similar note as point 3 above, on furthering the analysis of groups within groups, we also find a need for researchers to further problematize the classical socio-demographic measures used. If we go back to the papers presented in Table 3 - for instance, if we look at the paper discussing that citizens with a lower socioeconomic status use governmental services to a lesser degree [42] - is there a difference between the level of income these citizens have or which education they are missing? If immigrants are to be researched are their differences between which country the citizen has immigrated from? In the paper showing that gender, as in being a man or a woman, did not affect access to and use of eGovernment services [e.g., 20] - what would happen if other genders than man/woman were included in the analysis? We call for researchers, their models and methods, to be more informed and inclusive of e.g., transgendered citizens. From the researched papers there were no reporting of any of these suggested problematizations.

5. More research on policy implementation and practice. Whereas research papers on policies for diversity were quite few - only 7 papers in our study [e.g., 31, 32, 33] concerned policies - we found the few that did so to be highly relevant for making an impact on practice. Not only would we propose that more research is conducted at policy level, but also that when researchers are focusing policies, they make sure that they address how these policies are implemented in practice. One such study on policies [48] showed that whereas the existence of an accessibility policy did make people more sensitive towards disadvantaged populations, this awareness did not lead to any larger practical changes in the municipalities. For us to know this we need to track policies from the making to implementation.

6. Changing focus from use to development for diversity: As shown in Table 4, the majority of the papers (40) focuses on individuals' use of technology, services and various platforms. Less attention (16 papers) is paid to how we should design services to support individuals with different needs, backgrounds or cultures [e.g., 33, 38, 39]. As demonstrated by the vast number of papers on the topic (40 out of 55 in this study), we argue that we have a solid knowledge-base on the effects of technology in use in relation to diversity that we can build on, and that we need to change the focus to how we can, and should, design services to support those with different needs and prerequisites. This is indeed important when looking to the ongoing trends of automation in the public sector, as partially or fully automated services that rely on problematic assumptions of who the user is can result in anything from inconveniences to incorrect decisions. We argue that participatory approaches using e, g., action research or design science would benefit such approaches as it leaves room for including the excluded in the research and furthermore in the design of services, which could lead to benefits such as personalized services, more 
innovative solutions and development of services that users see value in [39].

\section{Conclusion}

This study set out to describe how diversity among citizens is addressed in eGovernment research. First of all, our investigation into the topic showed that there is no common understanding of the concept 'diversity' in our field, so we call attention to the necessity of generating a shared understanding of diversity in eGovernment. Our results showed that the most common application domain was e-services with access and use as the most common unit of analysis. The most frequently researched groups are based on classical socio-demographic variables such as economy, level of education, age and gender and that this categorization was rarely broken down for further analysis such as groups within groups nor were any new groups, such as migrants, included. We also found that the vast majority of the papers discussed services in use, not forwardlooking towards what could, or should, be the case. The paper concluded by suggesting 6 needs for future research: conceptual clarity of the concept 'diversity'; focus underrepresented user groups; further the granularity in classical sociodemographic variables; identify groups within groups; target policies and policy implementation; and change focus from use to development.

\section{References}

[1] F. Adolfsson, "Försäkringskassan satsar på AI (In English: Social Insurance Agency invests in AI)," in SvD, ed. Voister, 2018.

[2] H. Evans, Hu, M., Kuchembuck, R., Gervet, E. , "Will you embrace AI fast enough?," AT Kearney Analysts, 2017. [Online]. Available: https://www.kearney.com/operations-performancetransformation/article/?/a/will-you-embrace-ai-fastenough-

[3] L. K. Larkey, "The development and validation of the workforce diversity questionnaire: An instrument to assess interactions in diverse workgroups," Management Communication Quarterly, vol. 9, no. 3, pp. 296-337, 1996.

[4] Q. M. Roberson, "Disentangling the meanings of diversity and inclusion in organizations," Group \& Organization Management, vol. 31, no. 2, pp. 212236, 2006.

[5] L. R. Wise and M. Tschirhart, "Examining empirical evidence on diversity effects: how useful is diversity research for public-sector managers?," Public Administration Review, vol. 60, no. 5, pp. 386-394, 2000.

[6] M. McDougall, "Equal opportunities versus managing diversity: another challenge for public sector management?," Int J Public Sect Ma, vol. 9, no. 5/6, pp. 62-72, 1996.

[7] R. K. Polat, "Digital exclusion in Turkey: A policy perspective," Government Information Quarterly, vol. 29, no. 4, pp. 589-596, 2012.

[8] E. Showers, N. Tindall, and T. Davies, "Equality of Participation Online Versus Face to Face: Condensed Analysis of the Community Forum Deliberative Methods Demonstration," in Electronic Participation: Proceedings of the 7th IFIP 8.5 International Conference on Electronic Participation (ePart 2015), E. Tambouris et al., Eds., ed. Thessaloniki, Greece: Springer International Publishing, 2015, pp. 53-67.

[9] D. Thakur, "Diversity in the Online Deliberations of NGOs in the Caribbean," Journal of Information Technology \& Politics, vol. 9, no. 1, pp. 16-30, 2011.

[10] D. Ferri and S. Favalli, "Web Accessibility for People with Disabilities in the European Union: Paving the Road to Social Inclusion," (in English), Societies, vol. 8, no. 2, pp. [1-19], 2018/06// 2018, doi: 10.3390/soc 8020040 .

[11] B. Niehaves, "Iceberg ahead: On electronic government research and societal aging," (in English), Government Information Quarterly, vol. 28, no. 3, pp. 310-319, Jul 2011, doi: 10.1016/j.giq.2011.01.003.

[12] J. C. Bertot, "Building Digitally Inclusive Communities: The Roles of Public Libraries in Digital Inclusion and Development," in 9th International Conference on Theory and Practice of Electronic Governance (ICEGOV '15-16), ed. New York, NY, USA: ACM, 2016, pp. 95-102.

[13] P. Silva, A. D. Matos, and R. Martinez-Pecino, "Einclusion: Beyond individual socio-demographic characteristics," (in English), Plos One, vol. 12, no. 9, pp. 1-10, Sep 14 2017, doi: ARTN e0184545 10.1371/journal.pone.0184545.

[14] A. C. Ramos, X. Mahou-Lago, and R. BouzasLorenzo, "Social Inclusion, E-Exclusion and ReDirecting Digital Development Policies," in 17th European Conference on Digital Government (ECDG 2017), ed. Lisbon, Portugal, 2017, pp. 163169.

[15] E. Wihlborg, K. Hedström, and H. Larsson, "eGovernment for all - Norm-critical Perspectives and Public Values in Digitalization," in Proceedings of the 50th Hawaii International Conference on System Science (HICSS-50), ed. Waikoloa Village, Hawaii, USA, 2017, pp. 2549-2558.

[16] J. Webster and R. T. Watson, "Analyzing the past to prepare for the future: Writing a literature review," MIS quarterly, pp. xiii-xxiii, 2002.

[17] Å. Grönlund and A. Andersson, "e-Gov research quality improvements since 2003: more rigor, but research (perhaps) redefined," in International Conference on Electronic Government, 2006: Springer, pp. 1-12. 
[18] S. Stemler, "An overview of content analysis," Practical assessment, research \& evaluation, vol. 7, no. 17, pp. 137-146, 2001.

[19] H.-F. Hsieh and S. E. Shannon, "Three approaches to qualitative content analysis," Qualitative health research, vol. 15, no. 9, pp. 1277-1288, 2005.

[20] Y.-T. Choi and S. Park, "Understanding gender inequality in central e-government: A Korean case study," (in English), Government Information Quarterly, vol. 30, no. 3, pp. 300-309, Jul 2013, doi: 10.1016/j.giq.2013.01.003.

[21] V. Constantinou, A. Ioannou, and P. Diaz, "Inclusive access to emergency services: an action research project focused on hearing-impaired citizens," Universal Access in the Information Society, vol. 16, no. 4, pp. 929-937, 2017.

[22] A. J. McDermott, J. C. Bertot, and P. T. Jaeger, "Digital Inclusion and the Affordable Care Act: Public Libraries, Politics, Policy, and Enrollment in "Obamacare"," Public Library Quarterly, vol. 34, no. 1, pp. 1-22, 2015.

[23] A. F. Barbosa, M. Pozzebon, and E. H. Diniz, "Rethinking E-Government Performance Assessment from a Citizen Perspective," (in English), Public Administration, vol. 91, no. 3, pp. 744-762, Sep 2013, doi: DOI 10.1111/j.14679299.2012.02095.x.

[24] F. Pethig and J. Krönung, "Social Inclusion through E-Government? Developing an Inclusionary Framework of E-Government Adoption," in 36th International Conference on Information Systems (ICIS 2015), ed. Fort Worth, TX, USA, 2015.

[25] P. White and N. Selwyn, "Moving On-Line? An Analysis of Patterns of Adult Internet Use in the UK, 2002-2010," Information, Communication \& Society, vol. 16, no. 1, pp. 1-27, 2013.

[26] E. Ferro, J. R. Gil-Garcia, and N. Helbig, "The Digital Divide Metaphor: Understanding Paths to IT Literacy," in Electronic Government: Proceedings of the 6th IFIP WG 8.5 International Conference, EGOV 2007 vol. 4656, M. A. Wimmer, J. Scholl, and A. Gronlund, Eds., ed. Regensburg, Germany, 2007, pp. 265-280

[27] A. Macintosh, "Characterizing e-participation in policy-making," in 37th Annual Hawaii International Conference on System Sciences, 2004. Proceedings of the, 2004: IEEE, p. 10 pp.

[28] H. P. McKenna, "Re-conceptualizing Social Inclusion in the Context of 21st Century Smart Cities," in Social inclusion and usability of ICTenabled services, J. Choudrie, P. Tsatsou, and S. Kurnia Eds. New York: Routledge, Taylor \& Francis Group, 2018, pp. [1-18].

[29] S. Scherer, C. Neuroth, G. Schefbeck, and M. A. Wimmer, "Enabling eParticipation of the Youth in the Public Debate on Legislation in Austria: A Critical Reflection," in Electronic Participation: Proceedings of the 1st IFIP WG 8.5 International Conference, ePart 2009 vol. 5694, A. Macintosh and E. Tambouris, Eds., ed. Linz, Austria, 2009, pp. 151-162.
[30] J. Schossböck et al., "Inclusion and Privacy in EParticipation Platform Design," in Electronic Government and Electronic Participation: Joint Proceedings of Ongoing Research and Projects of IFIP WG 8.5 EGOV and ePart 2016 vol. 23, ed. Guimarães, Portugal: IOS Press, 2016, pp. 51-58.

[31] P. T. Jaeger, "The Social Impact of an Accessible EDemocracy," Journal of Disability Policy Studies, vol. 15, no. 1, pp. 19-26, 2004. [Online]. Available: http://proquest.umi.com/pqdweb?did=935134841\& Fmt $=7 \&$ clientId $=8991 \&$ RQT $=309 \&$ VName $=$ PQD

[32] R. Zambrano, "E-Governance and Development: Service Delivery to Empower the Poor," International Journal of Electronic Government Research, vol. 4, no. 2, pp. 1-11, 2008.

[33] J. Shahin and M. Finger, "The operationalisation of e-governance," in 2nd International Conference on Theory and Practice of Electronic Governance (ICEGOV 2008), ed. Cairo, Egypt, 2008, pp. 24-30.

[34] D. Taylor and G. Packham, "Social Inclusion through ICT: Identifying and Overcoming Barriers to ICT Use," (in English), Strategic ChangeBriefings in Entrepreneurial Finance, vol. 25, no. 1, pp. 45-60, Jan 2016, doi: 10.1002/jsc.2046.

[35] S. J. Macdonald and J. Clayton, "Back to the future, disability and the digital divide," (in English), Disability \& Society, vol. 28, no. 5, pp. 702-718, Jul 1 2013, doi: Doi 10.1080/09687599.2012.732538.

[36] K. Axelsson and U. Melin, "Talking to, not about, citizens-Experiences of focus groups in public eservice development," in International Conference on Electronic Government, 2007: Springer, pp. 179190.

[37] D. Bell and M. Nusir, "Co-design for Government Service Stakeholders," in Proceedings of the 50th Hawaii International Conference on System Science (HICSS-50), ed. Waikoloa Village, Hawaii, USA, 2017, pp. 2539-2548.

[38] C. Folkerd and G. Spinelli, "User exclusion and fragmented requirements capture in publicly-funded IS projects," Transforming Government: People, Process and Policy, vol. 6, no. 1, pp. 32-49, 2009, doi: 10.1108/17506160910940722.

[39] C. Bridge, "Citizen Centric Service in the Australian Department of Human Services: The Department's Experience in Engaging the Community in Codesign of Government Service Delivery and Developments in E-Government Services," (in English), Aust J Publ Admin, vol. 71, no. 2, pp. 167177, Jun 2012, doi: DOI 10.1111/j.14678500.2012.00763.x.

[40] J. Harambam, S. Aupers, and D. Houtman, "The Contentious Gap: From digital divide to cultural beliefs about online interactions," (in English), Inform Commun Soc, vol. 16, no. 7, pp. 1093-1114, Sep 1 2013, doi: Doi 10.1080/1369118x.2012.687006.

[41] J. W. Weiss, G. J. J. Gulati, D. J. Yates, and L. E. Yates, "Mobile Broadband Affordability and the Global Digital Divide, An Information Ethics Perspective," in Proceedings of the 48th Hawaii 
International Conference on System Sciences (HICSS-48), ed, 2015, pp. 2177-2186.

[42] A. Dugdale, A. Daly, F. Papandrea, and M. Maley, "Accessing e-government: challenges for citizens and organizations," Int Rev Adm Sci, vol. 71, no. 1, pp. 109-118, 2005. [Online]. Available: http://proquest.umi.com/pqdweb?did=974903661\& Fmt $=7 \&$ clientId $=8991 \&$ RQT $=309 \&$ VName $=$ PQD

[43] A. Alsoud and K. Nakata, "Towards a Life-event Oriented G2C E-Service Provision: the NoBLE Framework," in 18th Americas Conference on Information Systems (AMCIS 2012), ed. Seattle, Washington, USA, 2012, pp. 1-10.

[44] J. J. P.-A. Hsieh, M. Keil, J. Holmstrom, and L. Kvasny, "The Bumpy Road to Universal Access: An Actor-Network Analysis of a U.S. Municipal Broadband Internet Initiative," (in English), Inform Soc, vol. 28, no. 4, pp. 264-283, 2012, doi: Doi 10.1080/01972243.2012.689271.

[45] B. Yu, A. Ndumu, J. Liu, and Z. Fan, "E-inclusion or digital divide: an integrated model of digital inequality," (in English), $J$ Doc, vol. 74, no. 3, pp. 552-574, 2018, doi: 10.1108/Jd-10-2017-0148.

[46] M. Sehli, P. Sarkar, and L. Young, "The Development of E-Hajj: Influence of Diversity Issues," in 20th Pacific Asia Conference on Information Systems (PACIS 2016), ed. Chiayi, Taiwan, 2016, pp. 1-14.

[47] A.-M. Hancock, Intersectionality: An intellectual history. Oxford University Press, 2016.

[48] P. M. A. Baker, A. Bell, and N. W. Moon, "Accessibility Issues in Municipal Wireless Networks," in Handbook of Research on Strategies for Local E-Government Adoption and Implementation: Comparative Studies, vol. 2, C. G. Reddick Ed., (Advances in Electronic Government Research (AEGR) M. Khosrow-Pour, Ed. Hershey, PA; London, UK: Information Science Reference, 2009, ch. 30, pp. 569-588. 